\title{
Clinical characteristics and role of whole- body bone scan in multifocal osteonecrosis
}

\author{
Young-Sil An ${ }^{1}$, Sunghoon Park², Ju-Yang Jung ${ }^{3}$, Chang-Hee Suh ${ }^{3}$ and Hyoun-Ah Kim ${ }^{3^{*}}$ (D)
}

\begin{abstract}
Background: Multifocal osteonecrosis (ON) is defined as ON involving three or more distinct anatomical sites. We investigated the clinical characteristics and utility of whole-body bone scans (WBBS) in patients with multifocal ON.

Methods: A total of 254 patients with ON confirmed by magnetic resonance imaging (MRI) or X-rays of the hips or other anatomic regions were evaluated using WBBS and divided into those with multifocal disease and those with oligofocal disease; their clinical characteristics were then compared. All data were analyzed retrospectively both visually and quantitatively (via uptake grading and defect scoring). Associations between the MRI Association Research Circulation Osseous (ARCO) classification and bone scan photon defects and uptake grade were assessed. Factors associated with multifocal ON were identified using logistic regression.

Results: Of the 254 ON patients, 26 (10.2\%) had multifocal ON. Their mean age (42.8 \pm 14.3 years) was less than that of patients with oligofocal ON (50.9 \pm 15.4 years; $p=0.011)$. Comorbidities, corticosteroid use, and treatment with immunosuppressive agents were more frequent in patients with multifocal ON. Age (odds ratio $[O R]=0.964, p=0.013$ ), the presence of a comorbidity ( $\mathrm{OR}=3.387, p=0.006)$, present corticosteroid use $(\mathrm{OR}=5.696, p<0.001)$, and treatment with immunosuppressive agents $(\mathrm{OR}=3.447, p=0.004)$ were significantly associated with multifocal ON. The MRI ARCO classification was not associated with photon defects in the bone scans of those with femoral ON. However, the ARCO classification was significantly associated with uptake grade.
\end{abstract}

Conclusions: WBBS may be an additional tool for evaluating ON patients with risk factors for multiple ON, such as younger age, corticosteroid use, and comorbidities.

Keywords: Osteonecrosis, Whole-body bone scan, Magnetic resonance imaging, Risk factor

\section{Background}

Osteonecrosis $(\mathrm{ON})$ is a serious disease that causes joint pain and significant physical disability. Various joints can be affected, including the shoulders, knees, and ankles, but the most commonly affected site is the hip $[1,2]$. Although the detailed pathogenesis of $\mathrm{ON}$ remains unclear, ON may reflect bony ischemia caused by direct injury or vascular damage [3]. Trauma, excessive alcohol intake, corticosteroid treatment, and rheumatic and malignant diseases contribute to the development of ON [4]. Multifocal ON, which $\mathrm{ON}$ involves three or more distinct anatomical sites [5], is rare, being seen in only approximately $3 \%$ of all ON patients [5]. Corticosteroid use is a known risk factor for multifocal ON [5, 6], as are certain comorbidities, including

\footnotetext{
*Correspondence: nakhada@naver.com

${ }^{3}$ Department of Rheumatology, Ajou University School of Medicine, Suwon, Korea

Full list of author information is available at the end of the article
}

systemic lupus erythematosus (SLE), renal failure, leukemia, and lymphoma [5, 7, 8]. However, almost all studies of multifocal $\mathrm{ON}$ are case reports and case series, so the incidence and clinical characteristics of the condition remain poorly defined [5, 8-13].

Imaging is used to diagnose $\mathrm{ON}$ and evaluate the severity of lesions. Radiographs are often used initially, but earlystage disease may not be detected because radiographic abnormalities develop only after prolonged ischemic change [14]. Magnetic resonance imaging (MRI) detects ON with high sensitivity and is used to assess the severity of the disease [15]. However, routine MRI does not cover all joints because of the high cost. A whole-body bone scan (WBBS) is more sensitive than a simple X-ray in terms of diagnosing ON [16-18]. A WBBS can be used to screen for multifocal ON, revealing abnormal bone uptake of Tc-99 phosphates [19]. However, bone scintigraphy is of low sensitivity when

(c) The Author(s). 2019 Open Access This article is distributed under the terms of the Creative Commons Attribution 4.0 International License (http://creativecommons.org/licenses/by/4.0/), which permits unrestricted use, distribution, and reproduction in any medium, provided you give appropriate credit to the original author(s) and the source, provide a link to the Creative Commons license, and indicate if changes were made. The Creative Commons Public Domain Dedication waiver (http://creativecommons.org/publicdomain/zero/1.0/) applies to the data made available in this article, unless otherwise stated. 
used to diagnose symptomatic ON [1]. Although several studies have reported bone scan data for ON patients, the results are inconsistent and limited to case reports or case series with small numbers of patients [1, 16-19].

Therefore, we retrospectively reviewed the medical records of ON patients and their WBBS, X-ray, and MRI data; identified those with multifocal $\mathrm{ON}$; and investigated the clinical characteristics and utility of WBBS in patients with multifocal $\mathrm{ON}$.

\section{Methods}

\section{Subjects}

We identified 294 patients among the computerized medical records held at Ajou University Hospital with the diagnostic code for ON and test code for WBBS; 40 patients were excluded because their diagnosis was not confirmed to $\mathrm{ON}$ and MRI findings were negative. We retrospectively reviewed data on 254 patients with $\mathrm{ON}$ confirmed by MRI or X-ray of the site at the time of their initial visit between 2003 and 2017. We reviewed the WBBS and the MRI or X-rays of the sites, such as hips, knees, ankles and shoulders. We divided the patients into multifocal and oligofocal ON groups. Multifocal ON was defined as $\mathrm{ON}$ involving three or more separate anatomical sites, as described previously [5]. A total of 26 patients diagnosed with multifocal ON were compared to the 228 remaining patients with a diagnosis of oligofocal $\mathrm{ON}$. The study was approved by our institutional review board (approval no. AJIRB-MED-MDB-18-041).

\section{Variables}

All clinical data were retrieved from medical records stored in the hospital database. Age, sex, all comorbidities, clinical symptoms and their duration, and previous treatment were recorded at the time of WBBS. The cumulative corticosteroid dose (prednisolone equivalent for all oral, intravenous, subcutaneous, and intramuscular administrations) during the WBBS was calculated. Excessive alcohol intake was defined as consumption of more than $400 \mathrm{~mL}$ of alcohol per week. Soju is a distilled Korean liquor; one bottle of Soju contains $72 \mathrm{~mL}$ of alcohol (i.e., $360 \mathrm{~mL}$ containing 20\% alcohol). Therefore, excessive alcohol intake can be defined as consumption of one bottle of Soju per day, or two bottles of Soju on 3 or more days per week. We divided the causes of $\mathrm{ON}$ into four categories: 1) idiopathic, 2) trauma, 3) a comorbidity requiring the use of corticosteroids or immunosuppressive agents, and 4) excessive alcohol intake.

\section{WBBS acquisition}

WBBS was performed $4 \mathrm{~h}$ after injection of $740 \mathrm{MBq}$ technetium-99 m hydroxymethylene diphosphonate (Tc-99 $\mathrm{m}$ HDP). Anterior and posterior views were acquired using a double-headed gamma camera equipped with a VariCam
Millennium VG low-energy high-resolution collimator (GE Medical Systems, Milwaukee, WI, USA). Images were analyzed on a Xeleris Workstation (GE Healthcare, Buckinghamshire, UK).

\section{WBBS image interpretation and analysis}

All WBBSs were analyzed visually by a specialist in nuclear medicine, with 14 years of experience (Y.S.A.), blind to all other clinical data. Bone regions exhibiting uptake were recorded, and the extent of the uptake was graded visually from 0 to $2(0=$ no uptake, $1=$ mild, $2=$ intense $)$. In addition, uptake was recorded as bilateral or unilateral. Photon defects were also noted.

\section{Simple radiographs and MRI}

Simple radiographs and MR images were obtained using standard imaging protocols featuring at least two projections or planes. MR imaging was performed using a 1.5-T (Signa HDxt, Signa Excite; GE Healthcare) or a $3 \mathrm{~T}$ (Achieva; Philips Healthcare, Best, The Netherlands) system fitted with commercial body or extremity coils depending on the location of the lesion. All sequences included fat-saturated T2weighted and T1-weighted images (non-contrast T1 and fat-suppressed contrast-enhanced T1 images).

\section{Simple radiograph and MR image interpretation and analysis}

A musculoskeletal radiologist with 10 years of experience (S.P.), blind to the clinical information evaluated simple radiographs and MR images. On a simple radiograph, ON was defined as a combination of sclerosis, cystic change, and a crescent-shaped, subchondral, lucent lesion [20]. On an MR image, a band-like, crescent-shaped, or sector-like region of bone marrow replacement and the double-line sign (an inner line of high signal intensity running parallel to an outer line of low signal intensity) were considered diagnostic of $\mathrm{ON}$, which was classified using the Association Research Circulation Osseous (ARCO) system [21].

\section{Statistical analyses}

All statistical analyses were performed using SPSS software (ver. 23.0; SPSS Inc., Chicago, IL, USA). $p<0.05$ was considered to reflect statistical significance. Results are presented as means \pm standard deviation (SD) for continuous variables and as frequencies with percentages for categorical variables. Independent Student's t-test was used to compare continuous variables, and Pearson's chi square test was used to compare categorical variables. Factors associated with multifocal ON were defined using logistic regression. The extent of the agreement between WBBS and hip MRI or X-ray images was evaluated using the kappa ( $\mathrm{k}$ ) statistic; $\mathrm{\kappa}>0.8$ represents excellent agreement, 
0.61-0.8 good agreement, $0.41-0.6$ moderate agreement, $0.21-0.4$ fair agreement, and $<0.2$ poor agreement [22]

\section{Results}

\section{Clinical characteristics of patients with multifocal and oligofocal ON}

Table 1 lists the clinical characteristics of the 254 patients with ON confirmed by MRI or X-ray. Their mean age was $50.0 \pm 15.4$ years, and $152(59.8 \%)$ were male. A total of 26 patients (10.2\%) had multifocal ON as shown by WBBS and MRI or X-ray. Twenty-four patients had multifocal ON evident on WBBS and MRI or X-ray. In the other two patients, multifocal ON was confirmed by multifocal site evaluation by MRI or X-rays, with negative results on WBBS. The mean age of patients with multifocal ON (42.8 \pm 14.3 years) was less than that of patients with oligofocal ON $(50.9 \pm 15.4$ years; $p=0.011)$. Accompanying comorbidities were more common in patients with multifocal ON $(n=18,69.2 \%)$ than oligofocal ON ( $n=91,39.9 \% ; p=0.006)$. Current corticosteroid use was more common in those with multifocal ON (16, $61.5 \%)$ than oligofocal ON (50, 21.9\%; $p<0.001)$. However, cumulative corticosteroid dose did not differ between the groups $(p=0.859)$. Immunosuppressive agents were more commonly taken by patients with multifocal ON $(11,42.3 \%)$ than oligofocal ON $(40,17.5 \% ; p=0.007)$. Table 2 lists the causes of $\mathrm{ON}$. The most common cause of multifocal $\mathrm{ON}$ was a comorbidity requiring the use of corticosteroids or immunosuppressive agents $(18,69.2 \%)$; the other causes were idiopathic $(4,15.4 \%)$, alcohol intake $(3,11.5 \%)$, and trauma $(1,3.8 \%)$. The most common cause of oligofocal ON was excessive alcoholic intake (74, $32.5 \%$ ), followed by a comorbidity requiring the use of corticosteroids or immunosuppressive agents (70,30.7\%), idiopathic causes $(60,26.3 \%)$, and trauma $(24,10.5 \%)$. The most common cause of ON thus differed for multifocal and oligofocal ON $(p=0.001)$. Table 3 lists the comorbidities in all patients. Figure 1 shows ON sites confirmed by WBBS and MRI or X-rays in all 254 patients.

\section{Factors associated with multifocal ON}

We evaluated factors associated with multifocal $\mathrm{ON}$ (Table 4). Age (odds ratio $[\mathrm{OR}]=0.964, p=0.013$ ), comorbidity $(\mathrm{OR}=3.387, p=0.006)$, corticosteroid use $(\mathrm{OR}=$ 5.696, $p<0.001)$, and treatment with immunosuppressive agents $(\mathrm{OR}=3.447, p=0.004)$ were significantly associated with multifocal $\mathrm{ON}$ in univariate analyses. Age $(\mathrm{OR}=0.967$, 95\% confidence interval $[\mathrm{CI}]: 0.940-0.994, p=0.017)$ and

Table 1 Clinical characteristics of multifocal and oligofocal osteonecrosis (ON) in 254 patients with ON

\begin{tabular}{|c|c|c|c|c|}
\hline & $\begin{array}{l}\text { Multifocal ON } \\
(n=26)\end{array}$ & $\begin{array}{l}\text { Oligofocal ON } \\
(n=228)\end{array}$ & $\begin{array}{l}\text { Any ON } \\
(N=254)\end{array}$ & $p$-value \\
\hline Age (years) & $42.8 \pm 14.3$ & $50.9 \pm 15.4$ & $50.0 \pm 15.4$ & 0.011 \\
\hline $\operatorname{Sex}(M / F)$ & $15(57.7) / 11(42.3)$ & $137(60.1) / 91$ (39.9) & $152(59.8) / 102(40.2)$ & 0.835 \\
\hline Smoking (yes) & $7(26.9)$ & $94(41.2)$ & $101(39.8)$ & 0.205 \\
\hline Alcohol use (excessive) & $10(38.5)$ & $104(45.6)$ & $114(44.9)$ & 0.538 \\
\hline Diabetes mellitus & $3(11.5)$ & $11(4.8)$ & $14(5.5)$ & 0.162 \\
\hline Hypertension & $10(38.5)$ & $54(23.7)$ & $64(25.2)$ & 0.150 \\
\hline Trauma & $1(3.8)$ & $37(16.2)$ & $38(15.0)$ & 0.007 \\
\hline Symptom sites (n) & $1.92 \pm 1.26$ & $1.26 \pm 0.44$ & $1.33 \pm 0.61$ & 0.014 \\
\hline Symptom duration (months) & $7.0 \pm 9.3$ & $7.5 \pm 13.7$ & $7.4 \pm 13.3$ & 0.855 \\
\hline Comorbidity & $18(69.2)$ & $91(39.9)$ & $109(42.9)$ & 0.006 \\
\hline Comorbidity duration (years) & $6.37 \pm 6.77$ & $6.74 \pm 6.80$ & $6.68 \pm 6.77$ & 0.833 \\
\hline Use of CS & $16(61.5)$ & $50(21.9)$ & $66(26.0)$ & $<0.001$ \\
\hline Maximal dose of CS & $284.4 \pm 427.3$ & $154.0 \pm 317.0$ & $185.6 \pm 347.9$ & 0.273 \\
\hline Cumulative dose of CS & $5310.7 \pm 5359.6$ & $5704.8 \pm 7664.7$ & $5612.8 \pm 7153.0$ & 0.859 \\
\hline Use of immunosuppressive agents & $11(42.3)$ & $40(17.5)$ & $51(20.1)$ & 0.007 \\
\hline Osteoporosis & $1(3.8)$ & $12(5.3)$ & $13(5.1)$ & $>0.999$ \\
\hline Use of BP & $1(3.8)$ & $10(4.4)$ & $11(4.3)$ & $>0.999$ \\
\hline BP duration (months) & 24 & $49.7 \pm 18.5$ & $47.4 \pm 19.2$ & \\
\hline ON sites confirmed by X-ray and MRI & $3.04 \pm 1.42$ & $1.52 \pm 0.53$ & $1.68 \pm 0.81$ & $<0.001$ \\
\hline ON sites confirmed by bone scan & $4.15 \pm 2.05$ & $1.27 \pm 0.53$ & $1.57 \pm 1.20$ & $<0.001$ \\
\hline
\end{tabular}

ON osteonecrosis, CS corticosteroid, BP bisphosphonate, $M R I$ magnetic resonance imaging. All values are presented as numbers (\%) or means \pm SD. Independent Student's $t$-test was used to compare continuous variables, and Pearson's chi square test was used to compare categorical variables between multifocal and oligofocal ON 
Table 2 Causes of multifocal and oligofocal osteonecrosis (ON) in patients with $\mathrm{ON}$

\begin{tabular}{|c|c|c|c|c|}
\hline Cause of ON & $\begin{array}{l}\text { Multifocal } \\
\text { ON } \\
(n=26)\end{array}$ & $\begin{array}{l}\text { Oligofocal } \\
\text { ON } \\
(n=228)\end{array}$ & $\begin{array}{l}\text { Any ON } \\
(N=254)\end{array}$ & $p$-value \\
\hline Idiopathic & $4(15.4)$ & $60(26.3)$ & $64(25.2)$ & 0.001 \\
\hline Trauma & $1(3.8)$ & $24(10.5)$ & $25(9.8)$ & \\
\hline $\begin{array}{l}\text { Comorbidity requiring } \\
\text { corticosteroids and } \\
\text { immunosuppressive } \\
\text { agents }\end{array}$ & $18(69.2)$ & 70 (30.7) & 88 (34.6) & \\
\hline $\begin{array}{l}\text { Excessive alcohol } \\
\text { intake }\end{array}$ & $3(11.5)$ & $74(32.5)$ & 77 (30.3) & \\
\hline
\end{tabular}

ON osteonecrosis. Pearson's chi square test was used to compare causes of multifocal and oligofocal ON

comorbidity (OR $=2.674,95 \%$ CI: $1.033-6.922, p=0.043)$ were significantly associated with multifocal $\mathrm{ON}$ in a multivariate logistic regression that also evaluated alcohol intake and trauma. Corticosteroid use $(\mathrm{OR}=4.512,95 \% \mathrm{CI}$ : $1.702-11.964, p=0.002)$ was significantly associated with multifocal $\mathrm{ON}$ in a multivariate logistic regression that also included alcohol intake, trauma, and corticosteroid use. However, only age ( $\mathrm{OR}=0.969$, 95\% CI: $0.941-$ 0.997, $p=0.028$ ) was associated with multifocal $\mathrm{ON}$ in multivariate analyses that included age, alcohol intake, trauma, and the use of immunosuppressive agents. Figure 2 shows the WBBS, MRI, and X-ray of a case of multifocal ON.

\section{WBBS, MRI, and X-ray results}

Both WBBS and local MRI images were obtained for 458 sites, and 456 sites were evaluated with WBBS and X-ray images among the 294 patients who underwent WBBS with a code of ON. Therefore, a total of 458 sites were compared based on WBBS and MR images, and 456 were compared based on WBBS and X-ray images (Table 5). WBBS was positive for 346 sites (75.5\%), and the MRI for 419 (91.4\%). Of the 458 sites, WBBS and MRI were in agreement for 369 . The $k$ coefficient of agreement between WBBS and MRI data was fair $(\kappa=0.325, p<$ $0.001)$. WBBS was positive for 348 (76.3\%) of the 456 sites, and the X-rays for 326 (71.4\%). Of the 456 sites, WBBS and $\mathrm{X}$-rays were in agreement for 362 . The coefficient of agreement was moderate $(\kappa=0.467, p<0.001)$.

We explored possible associations between WBBS uptake grade/defects and the ARCO classification, as determined by MRI (Table 6). The uptake grade was associated with the ARCO classification $(r=0.491, p<0.001)$, but uptake defects were not $(r=-0.032, p=0.496)$.

\section{Discussion}

We found that $10.2 \%$ of ON patients had multifocal ON associated with younger age, comorbidities, and the use of corticosteroids and immunosuppressive agents. Agreement
Table 3 Comorbidities in patients with multifocal and oligofocal osteonecrosis (ON)

\begin{tabular}{|c|c|c|c|}
\hline Comorbidity & $\begin{array}{l}\text { Multifocal } \\
\text { ON } \\
(n=18 / 26)\end{array}$ & $\begin{array}{l}\text { Oligofocal } \\
\text { ON } \\
(n=70 / 228)\end{array}$ & $\begin{array}{l}\text { Any } \\
\text { ON } \\
(N= \\
88 / \\
254)\end{array}$ \\
\hline Immune system disease & 8 & 26 & 34 \\
\hline Ulcerative colitis & 1 & & 1 \\
\hline Rheumatoid arthritis & & 5 & 5 \\
\hline AOSD & & 1 & 1 \\
\hline Systemic lupus erythematosus & 3 & 7 & 10 \\
\hline MCD, MGN, IgA nephropathy & 2 & 7 & 9 \\
\hline ANCA-associated vasculitis & 1 & 1 & 2 \\
\hline Dermatomyositis & & 3 & 3 \\
\hline $\begin{array}{l}\text { Sarcoidosis, Behçet's disease, } \\
\text { vitalism }\end{array}$ & 1 & 2 & 3 \\
\hline ESRD with KT & 3 & 6 & 9 \\
\hline Malignancy & 2 & 16 & 18 \\
\hline Lung cancer & & 1 & 1 \\
\hline Stomach cancer & 1 & 2 & 3 \\
\hline Renal cancer & & 2 & 2 \\
\hline Breast cancer & 1 & 5 & 6 \\
\hline Neuroblastoma & & 2 & 2 \\
\hline Rectal cancer & & 2 & 2 \\
\hline Gall bladder cancer & & 1 & 1 \\
\hline Hepatocellular carcinoma & & 1 & 1 \\
\hline Hematological diseases & & 4 & 4 \\
\hline Acute myelocytic leukemia & & 1 & 1 \\
\hline Multiple myeloma & & 1 & 1 \\
\hline Aplastic anemia & & 2 & 2 \\
\hline $\begin{array}{l}\text { Mitral valve stenosis, with } \\
\text { operation }\end{array}$ & & 1 & 1 \\
\hline $\begin{array}{l}\text { Spinal cord tumor, meningioma, } \\
\text { pheochromocytoma }\end{array}$ & 1 & 2 & 3 \\
\hline Craniopharyngioma, seizure & 1 & 1 & 2 \\
\hline $\begin{array}{l}\text { Osteoporosis with bisphosphonate } \\
\text { treatment }\end{array}$ & & 2 & 2 \\
\hline Bronchiectasis & & 1 & 1 \\
\hline $\begin{array}{l}\text { Facial palsy, hearing loss, } \\
\text { trigeminal neuralgia }\end{array}$ & 1 & 2 & 3 \\
\hline $\begin{array}{l}\text { Recurrent oral ulcer, recurrent } \\
\text { uveitis }\end{array}$ & 1 & 1 & 2 \\
\hline $\begin{array}{l}\text { Allergic disease (urticarial, } \\
\text { Steven-Johnson), vitalism, } \\
\text { asthma }\end{array}$ & 1 & 5 & 6 \\
\hline $\begin{array}{l}\text { Liver cirrhosis, intraperitoneal } \\
\text { bleeding }\end{array}$ & & 3 & 3 \\
\hline
\end{tabular}

ON osteonecrosis, AOSD adult onset Still's disease, $M C D$ minimal change disease, MGN membranous glomerulonephritis, ANCA anti-neutrophil cytoplasmic antibody, ESRD end-stage renal disease, $K T$ kidney transplantation 


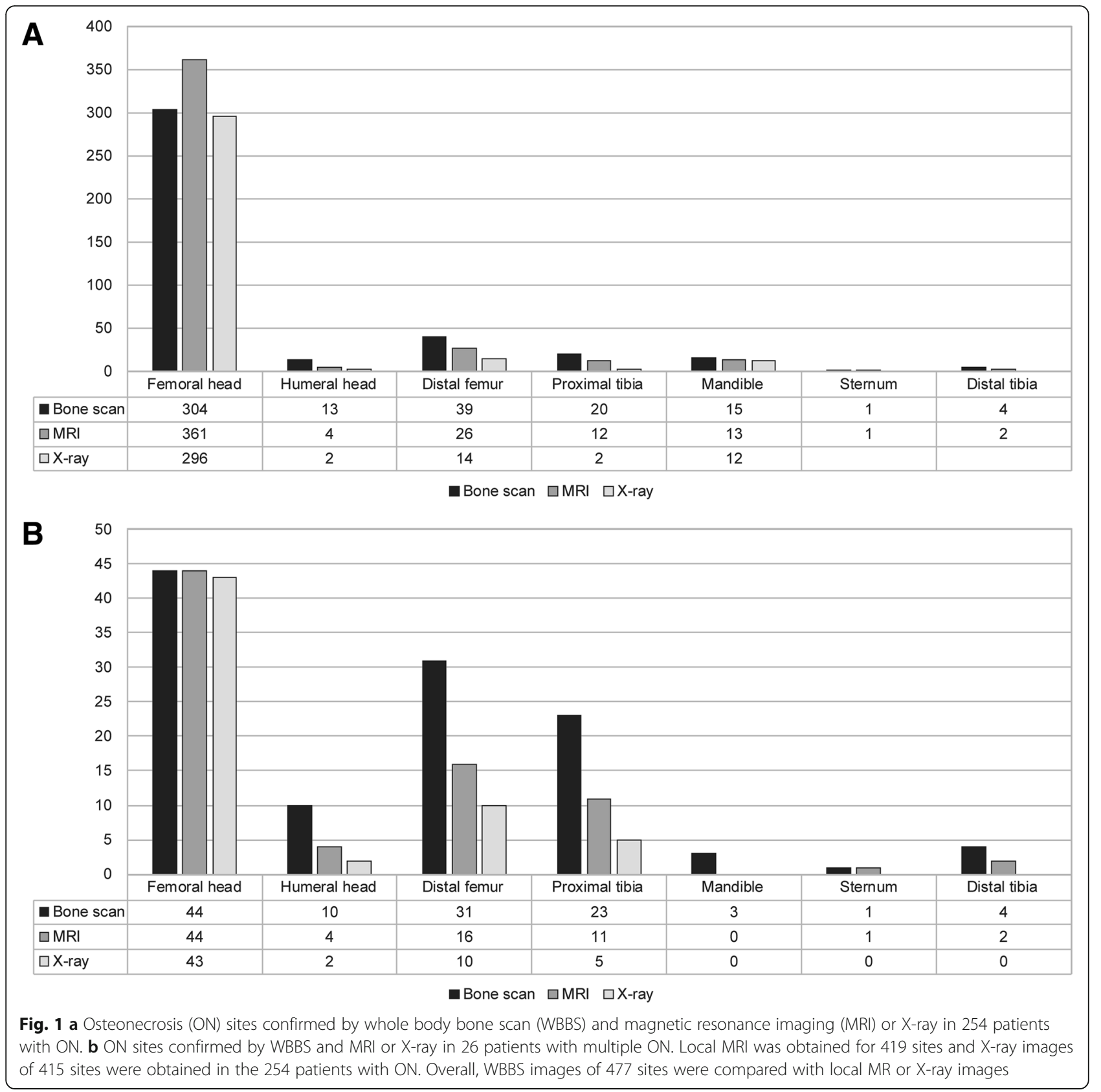

Table 4 Logistic regression analyses of factors associated with multifocal osteonecrosis (ON) in patients with ON

\begin{tabular}{|c|c|c|c|c|c|c|c|c|c|c|c|c|}
\hline \multirow{3}{*}{$\begin{array}{l}\text { Clinical factor } \\
\text { Age }\end{array}$} & \multicolumn{3}{|c|}{ Univariate } & \multirow{3}{*}{$\begin{array}{l}p \text {-value } \\
0.013\end{array}$} & \multicolumn{3}{|c|}{ Multivariate } & \multirow{3}{*}{$\begin{array}{l}p \text {-value } \\
0.017\end{array}$} & \multicolumn{3}{|c|}{ Multivariate } & \multirow{3}{*}{$\frac{p \text {-value }}{0.149}$} \\
\hline & \multirow{2}{*}{$\begin{array}{l}\mathrm{OR} \\
0.964\end{array}$} & \multicolumn{2}{|c|}{$95 \%$ Wald Cl } & & \multirow{2}{*}{$\begin{array}{l}\text { OR } \\
0.967\end{array}$} & \multicolumn{2}{|c|}{$95 \%$ Wald Cl } & & \multirow{2}{*}{$\begin{array}{l}\mathrm{OR} \\
0.978\end{array}$} & \multicolumn{2}{|c|}{ 95\% Wald Cl } & \\
\hline & & 0.937 & 0.992 & & & 0.940 & 0.994 & & & 0.950 & 1.008 & \\
\hline Alcohol abuse & 0.745 & 0.324 & 1.712 & 0.488 & 0.894 & 0.360 & 2.219 & 0.810 & 1.131 & 0.438 & 2.917 & 0.799 \\
\hline Trauma history & 0.206 & 0.027 & 1.571 & 0.128 & 0.273 & 0.034 & 2.188 & 0.273 & 0.257 & 0.033 & 2.024 & 0.197 \\
\hline Comorbidity & 3.387 & 1.413 & 8.118 & 0.006 & 2.674 & 1.033 & 6.922 & 0.043 & - & & & \\
\hline Use of corticosteroids & 5.696 & 2.434 & 13.328 & $<0.001$ & - & & & & 4.512 & 1.702 & 11.964 & 0.002 \\
\hline Use of immunosuppressive agents & 3.447 & 1.474 & 8.061 & 0.004 & - & & & & - & & & \\
\hline
\end{tabular}




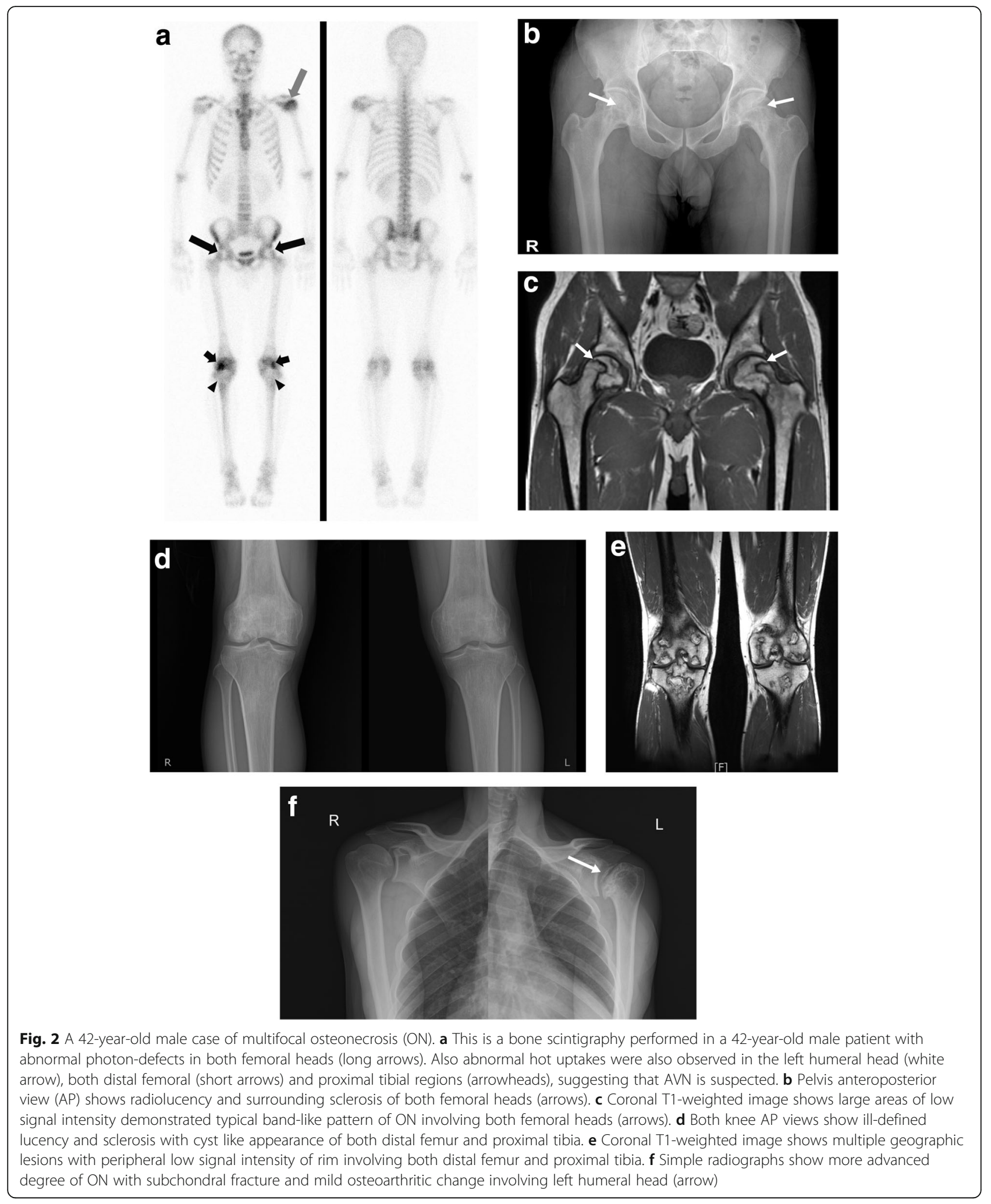


Table 5 Agreement between whole-body bone scan (WBBS) data and magnetic resonance imaging (MRI) and X-ray data in patients with osteonecrosis (ON)

\begin{tabular}{lllll}
\hline & & \multicolumn{2}{c}{ ON confirmed by bone scan } & Total \\
\cline { 2 - 4 } & & $(-)$ & $(+)$ & \\
\hline ON confirmed by MRI & $(-)$ & $31(6.8)$ & $8(1.7)$ & 39 \\
& $(+)$ & $81(17.7)$ & $338(80.7)$ & 419 \\
Total & & 112 & 346 & 458 \\
ON confirmed by X-ray & $(-)$ & $72(15.8)$ & $58(12.7)$ & 130 \\
& $(+)$ & $36(11.0)$ & $290(63.6)$ & 326 \\
Total & & 108 & 348 & 456 \\
\hline
\end{tabular}

$\mathrm{K}=0.325$ between bone scan and MRI $(p<0.001) ; \mathrm{K}=467$ between bone scan and X-ray $(p<0.001)$

between WBBS and MRI for all patients was fair, but the agreement between WBBS and X-rays was moderate. The ARCO score was significantly associated with the WBBS uptake grade.

Trauma and nontraumatic factors (excessive alcohol intake, corticosteroid use, and HIV infection) cause ON $[2,3]$. Corticosteroid and alcohol use are responsible for more than $90 \%$ of all cases of ON [3]. Other causes include hypercoagulable conditions and radiation therapy [23]. We classified the causes of $\mathrm{ON}$ into four categories: idiopathic, trauma, comorbidities requiring the use of corticosteroids or immunosuppressive agents, and excessive alcohol intake. The principal causes were excessive alcohol intake (30.3\%) and comorbidities requiring corticosteroid and/or immunosuppressive treatment $(34.6 \%)$, similar to what was found in previous studies. Comorbidities included several diseases of the immune system, including SLE, dermatomyositis, and ulcerative colitis; malignancy; kidney transplantation to treat end-stage renal disease; and hematological conditions. We also included benign conditions requiring corticosteroids (aphthous ulcer, recurrent uveitis, facial palsy, and several allergic diseases) as comorbidities.

Multifocal ON is uncommon,being observed in only 3$11 \%$ of ON patients [5]. It was associated in several case studies and case reports with high-dose corticosteroid therapy, high alcohol intake, several immune system diseases (including SLE), organ transplantation, and malignancy $[6,8,9,12,24]$. Earlier studies were (prospective or retrospective) observational studies performed during treatment and follow-up in patients with sickle-cell disease, acute lymphocytic leukemia, and non-Hodgkin disease [25-27]. The incidence of multifocal ON was $44-82 \%$. In this study, we did not evaluate the development of $\mathrm{ON}$ in patients at risk; rather, we found on review that $10.2 \%$ of $254 \mathrm{ON}$ patients had multifocal $\mathrm{ON}$ as evidenced by WBBS and MR or X-ray images. Their mean age (42.8 \pm 14.3 years) was less than that of patients with oligofocal ON $(50.9 \pm 15.4$ years; $p=0.011)$. Furthermore, the most common causes of multifocal ON differed from those of oligofocal ON. Most former patients (69.2\%) had comorbidities including systemic immune diseases, had undergone kidney transplantation, or had malignancies. Three patients consumed alcohol excessively, one patient had experienced severe trauma, and the causes of $\mathrm{ON}$ in four patients were unknown. We found that younger age, comorbidity, and use of corticosteroids and immunosuppressive agents were associated with multifocal ON. Several studies found that corticosteroid treatment, various rheumatic diseases, and hematological disease were so associated $[5,8,11]$. We derived ORs for the relevant factors: current corticosteroid use alone was highly significant in this context $(\mathrm{OR}=4.512)$, but neither the cumulative nor maximal dose of corticosteroids differed between those with multifocal and oligofocal ON.

Conventional MRI is the most sensitive and specific imaging modality for early diagnosis and evaluation of ON progression [15]. However, the cost is high, and it is not yet covered by national health insurance in Korea. MRI can be used to evaluate one or two symptomatic lesions, but not all symptom-free areas can be examined, even if multifocal $\mathrm{ON}$ is suspected. A recent study assessed the utility of coronal, short-tau inversion recovery, wholebody MRI (STIR-WBMI) for evaluating ON in 15 patients with myositis [28]; STIR-WBMRI detected early multifocal

Table 6 Associations between uptake grade of, or defect evident on, whole-body bone scan (WBBS) and Association Research Circulation Osseous (ARCO) classifications on magnetic resonance imaging (MRI)

\begin{tabular}{|c|c|c|c|c|c|c|c|c|c|}
\hline \multirow[t]{2}{*}{ ARCO } & \multicolumn{3}{|c|}{ Uptake grade of WBBS } & \multirow[t]{2}{*}{ Total } & \multirow[t]{2}{*}{$p$-value } & \multicolumn{2}{|c|}{ WBBS Photon defect } & \multirow[t]{2}{*}{ Total } & \multirow[t]{2}{*}{$p$-value } \\
\hline & 0 & 1 & 2 & & & $(-)$ & $(+)$ & & \\
\hline$\overline{0}$ & 32 & 5 & 2 & 39 & \multirow{6}{*}{$\begin{array}{l}0.491 \\
<0.001\end{array}$} & 5 & 34 & 39 & \multirow{6}{*}{$\begin{array}{l}-0.032 \\
0.496\end{array}$} \\
\hline 1 & 30 & 11 & 17 & 58 & & 14 & 44 & 58 & \\
\hline 2 & 54 & 66 & 69 & 189 & & 80 & 109 & 189 & \\
\hline 3 & 9 & 33 & 101 & 143 & & 39 & 104 & 143 & \\
\hline 4 & 0 & 9 & 20 & 29 & & 10 & 19 & 29 & \\
\hline Total & 125 & 124 & 209 & 458 & & 148 & 310 & 458 & \\
\hline
\end{tabular}

WBBS whole-body bone scan, ARCO Association Research Circulation Osseous 
ON. However, further studies with larger populations are needed. A recent study used whole-body MRI to evaluate 42 patients with Hodgkin lymphoma treated by chemotherapy. Of the 48 osteonecrotic lesions observed, $48 \%$ were detected in the knees, and multifocal ON was detected in six of seven patients (86\%) [29]. Furthermore, the metadiaphysis was involved more frequently than the epiphysis ( $40 \%$ vs. $33 \%$ ). As a result, whole-body MRI could be a very helpful tool for early detection of multifocal osteonecrotic lesions, but it is also expensive and is not yet covered by national health insurance in Korea. WBBS may be useful for diagnosing $\mathrm{ON}[16,30]$. WBBS is relatively inexpensive, and is easier to perform than MRI. However, several recent studies found that MRI was more sensitive $[15,31]$. Another study found that WBBS was less sensitive than MRI for diagnosing symptomatic ON [1]. Although all 163 patients with histologically confirmed lesions were identified by MRI, only $56 \%$ were confirmed by WBBS. In our study, the extent of agreement between MRI and WBBS data was fair $(\kappa=0.325)$. However, 346 of 419 MRI-identified lesions were confirmed by WBBS (80.7\%). Furthermore, the ARCO classification was significantly associated with femoral bone uptake grade on WBBS. In addition, WBBS identified 24 of 26 patients with multifocal ON (92.3\%). Therefore, WBBS may be an additional tool for diagnosing $\mathrm{ON}$ and assessing its progression, especially in patients with suspected multifocal ON.

Our study has several limitations. First, this was a retrospective cross-sectional work. Second, we lacked bone biopsy data and instead used MRI or X-ray data to locate affected sites. Third, in patients with multifocal $\mathrm{ON}$, not all $\mathrm{ON}$ sites were evaluated using MRI or $\mathrm{X}$-ray. Fourth, selection bias may have been in play; we reviewed medical records. Corticosteroids are a major cause of ON. Therefore, patients treated with corticosteroids may undergo more WBBS than those not treated with corticosteroids, which may have resulted in selection bias in this study. Fourth, the ON sites were not evaluated according to the lesion location, such as the metadiaphyseal or epiphyseal regions, as described previously [29]. However, most lesions of the patients with ON were located in epiphyseal regions, and only seven patients had metadiaphyseal ON without epiphyseal ON. Twenty-three patients with ON had metadiaphyseal and epiphyseal ON. This was probably due to MRI being expensive in Korea, so that only the symptomatic sites were evaluated. However, this is the first study to calculate ORs for the risks associated with corticosteroid therapy and comorbidities in terms of multifocal $\mathrm{ON}$, and to correlate quantitative bone scan data with the MRI ARCO classification of femoral head ON, which is representative of epiphyseal ON, in patients with ON. Our findings suggest that WBBS could play a useful role in the evaluation of multifocal $\mathrm{ON}$.

\section{Conclusions}

Multifocal ON is not uncommon. Age, comorbidity, and use of corticosteroids and immunosuppressive agents were significantly associated with multifocal ON. The ARCO classification correlated significantly with the bone uptake grade but not with photon defects. WBBS may be an additional tool for evaluating ON patients with risk factors for multiple $\mathrm{ON}$, such as younger age, corticosteroid use, and comorbidities.

\section{Abbreviations \\ ARCO: Association Research Circulation Osseous; MRI: Magnetic resonance imaging; ON: Osteonecrosis; SD: Standard deviations; SLE: Systemic lupus erythematosus; STIR-WBMI: Short-tau inversion recovery, whole-body MRI; TC- 99 m HDP: Technetium-99 m hydroxymethylene diphosphonate; \\ WBBS: Whole-body bone scan}

\section{Acknowledgements}

Not applicable

\section{Funding}

This research was supported by a grant of the Korea Health Technology R\&D Project through the Korea Health Industry Development Institute (KHIDI), funded by the Ministry of Health \& Welfare, Republic of Korea (grant number: HI16C0992) for analysis and interpretation of data.

\section{Availability of data and materials}

All data were included in the manuscript.

\section{Authors' contributions}

Y-SA and H-AK conceived, designed the study, analyzed the data and wrote the paper; SP, J-YJ, and C-HS contributed materials and analyzed the data. All authors have read and approved the final manuscript.

\section{Ethics approval and consent to participate}

This study was approved by the Ajou University Hospital Institutional Review Board (IRB No. AJIRB-MED-MDB-18-041), and informed consent was waved

because of the study nature with retrospective study.

\section{Consent for publication}

Not applicable

\section{Competing interests}

The authors declare that they have no competing interests.

\section{Publisher's Note}

Springer Nature remains neutral with regard to jurisdictional claims in published maps and institutional affiliations.

\section{Author details}

'Department of Nuclear Medicine and Molecular Imaging, Ajou University School of Medicine, Suwon, Korea. ${ }^{2}$ Department of Radiology, Ajou University School of Medicine, Suwon, Korea. ${ }^{3}$ Department of Rheumatology, Ajou University School of Medicine, Suwon, Korea.

Received: 13 August 2018 Accepted: 2 January 2019

Published online: 15 January 2019

\section{References}

1. Mont MA, Ulrich SD, Seyler TM, Smith JM, Marker DR, McGrath MS, et al. Bone scanning of limited value for diagnosis of symptomatic oligofocal and multifocal osteonecrosis. J Rheumatol. 2008;35:1629-34.

2. Assouline-Dayan Y, Chang C, Greenspan A, Shoenfeld Y, Gershwin ME. Pathogenesis and natural history of osteonecrosis. Semin Arthritis Rheum. 2002;32:94-124.

3. Ruderman M, McCarty DJ Jr. ARTHRITIS ROUNDS. (4). Aseptic necrosis in systemic lupus erythematosus. Report of a CASE involving six joints. Arthritis Rheum. 1964;7:709-17. 
4. Mankin HJ. Nontraumatic necrosis of bone (osteonecrosis). N Engl J Med. 1992;326:1473-9.

5. LaPorte DM, Mont MA, Mohan V, Jones LC, Hungerford DS. Multifocal osteonecrosis. J Rheumatol. 1998;25:1968-74.

6. Glueck CJ, Freiberg RA, Boppana S, Wang P. Thrombophilia, hypofibrinolysis, the eNOS T-786C polymorphism, and multifocal osteonecrosis. J Bone Joint Surg Am. 2008;90:2220-9.

7. Sun W, Shi Z, Gao F, Wang B, Li Z. The pathogenesis of multifocal osteonecrosis. Sci Rep. 2016;6:29576

8. Jeong HJ, Kim D, Cho SK, Kim Y, Bae SC, Sung YK. Clinical characteristics of multifocal osteonecrosis in Korean patients with rheumatic disease. Int J Rheum Dis. 2018;21:1301-8.

9. Flouzat-Lachaniete $\mathrm{CH}$, Roussignol X, Poignard A, Mukasa MM, Manicom O, Hernigou P. Multifocal joint osteonecrosis in sickle cell disease. Open Orthop J. 2009:3:32-5.

10. Gomez-Puerta JA, Peris P, Reverter JC, Espinosa G, Martinez-Ferrer A, Monegal $A$, et al. High prevalence of prothrombotic abnormalities in multifocal osteonecrosis: description of a series and review of the literature. Medicine (Baltimore). 2013;92:295-304.

11. Fajardo-Hermosillo LD, Lopez-Lopez L, Nadal A, Vila LM. Multifocal osteonecrosis in systemic lupus erythematosus: case report and review of the literature. BMJ Case Rep. 2013;2013:bcr2013008980.

12. Mullan RH, Ryan PF. Multiple site osteonecrosis in HIV infection. Rheumatology (Oxford). 2002;41:1200-2.

13. Mundo J, Peris P, Monegal A, Navasa M, Cervera R, Guaniabens N. Multifocal avascular necrosis after liver transplantation: an unusual presentation of the antiphospholipid syndrome. Lupus. 2006;15:304-7.

14. Grigoriu V, Stefaniu A, Fica N. Evolution of a bronchial foreign body (a tooth chip). Rev Chir Oncol Radiol O R L Oftalmol Stomatol Otorinolaringol. 1985:30:311-4.

15. Hauzeur JP, Pasteels $J$, Schoutens A, Hinsenkamp M, Appelboom T, Chochrad I, et al. The diagnostic value of magnetic resonance imaging in non-traumatic osteonecrosis of the femoral head. J Bone Joint Surg Am. 1989:71:641-9.

16. Alavi A, McCloskey JR, Steinberg ME. Early detction of avascular necrosis of the femoral head by $99 \mathrm{~m}$ technetium diphosphonate bone scan: a preliminary report. Clin Orthop Relat Res. 1977;(127):137-41.

17. Conklin JJ, Alderson PO, Zizic TM, Hungerford DS, Densereaux JY, Gober A et al. Comparison of bone scan and radiograph sensitivity in the detection of steroid-induced ischemic necrosis of bone. Radiology. 1983;147:221-6.

18. Gregg PJ, Walder DN. Scintigraphy versus radiography in the early diagnosis of experimental bone necrosis, with special reference to caisson disease of bone. J Bone Joint Surg Br. 1980;62-b:214-21.

19. Minoves M, Riera E, Costansa JM, Bassa P, Setoain J, Domenech FM. Multiple aseptic bone necrosis detected by Tc-99m MDP bone scintigraphy in a patient with systemic lupus erythematosus on corticosteroid therapy. Clin Nucl Med. 1998:23:48-9.

20. Choi HR, Steinberg ME, Y Cheng E. Osteonecrosis of the femoral head: diagnosis and classification systems. Curr Rev Musculoskelet Med 2015; 8: 210-220.

21. Osseous AARC. Committee on terminology and classification. ARCO News. 1992:41-6.

22. Landis JR, Koch GG. An application of hierarchical kappa-type statistics in the assessment of majority agreement among multiple observers. Biometrics. 1977:33:363-74.

23. Jones JP Jr. Intravascular coagulation and osteonecrosis. Clin Orthop Relat Res. 1992:41-53.

24. Symptomatic multifocal osteonecrosis. A multicenter study. Collaborative osteonecrosis group. Clin Orthop Relat Res. 1999;(369):312-26.

25. Amin NL, Feltbower R, Kinsey S, Vora A, James B. Osteonecrosis in patients with acute lymphoblastic leukaemia: a national questionnaire study. BMJ Paediatr Open. 2017;1:e000122

26. Rossleigh MA, Smith J, Straus DJ, Engel IA. Osteonecrosis in patients with malignant lymphoma. A review of 31 cases. Cancer. 1986;58:1112-6.

27. Daltro G, Franco BA, Faleiro TB, Rosario DAV, Daltro PB, Fortuna V. Osteonecrosis in sickle cell disease patients from Bahia, Brazil: a crosssectional study. Int Orthop. 2018;19:158.

28. Zhen-Guo H, Min-Xing Y, Xiao-Liang C, Ran Y, He C, Bao-Xiang G, et al. Value of whole-body magnetic resonance imaging for screening multifocal osteonecrosis in patients with polymyositis/dermatomyositis. Br J Radiol. 2017;90:20160780.
29. Albano D, Patti C, La Grutta L, Grassedonio E, Mulè A, Brancatelli G, et al. Osteonecrosis detected by whole body magnetic resonance in patients with Hodgkin lymphoma treated by BEACOPP. Eur Radiol. 2017;27:2129-36.

30. D'Ambrosia RD, Shoji H, Riggins RS, Stadalnik RC, DeNardo GL. Scintigraphy in the diagnosis of osteonecrosis. Clin Orthop Relat Res. 1978;(130):139-43.

31. Mitchell MD, Kundel HL, Steinberg ME, Kressel HY, Alavi A, Axel L. Avascular necrosis of the hip: comparison of MR, CT, and scintigraphy. AJR Am J Roentgenol. 1986;147:67-71.
Ready to submit your research? Choose BMC and benefit from:

- fast, convenient online submission

- thorough peer review by experienced researchers in your field

- rapid publication on acceptance

- support for research data, including large and complex data types

- gold Open Access which fosters wider collaboration and increased citations

- maximum visibility for your research: over $100 \mathrm{M}$ website views per year

At $\mathrm{BMC}$, research is always in progress.

Learn more biomedcentral.com/submissions 